Maasse: Länge $39 \mathrm{Mm}$., Breite 26.

In der Umgegend Kiews ist sie nicht selten als Brutvogel, im Museum sind recht viele Gelege und Bälge.

192. Carbo cormoranus, Kormoran.

Wurde 1869 im September geschossen und von einem meiner Bekannten als Gans gekauft und gebraten, war aber natürlich ungeniessbar. - Mir wurde der Kopf zugeschickt. -

193. Podiceps cristatus, Haubensteissfuss.

Ist sehr gemein auf allen grösseren Teichen und Seen.

Ankunft 1867: 15. März. Abzug 1867: 20. October.

$\begin{array}{ll}1868: 26 . " & 1868: 26 . " \\ 1869: 12 . & 1869: 22 .\end{array}$

Am 28. Mai 1868 nahm ich auf dem Sokolowschen See 10 Gelege aus von 2-3 Eiern, die Nester waren alle im Schilfrohr in der Nähe von Inseln angelegt, und verliess das Weibchen, wenn es auf dem Neste sass, die Eier bei der Annäherung des Bootes tauchend und erst ausserhalb des Rohres aus dem Wasser hervorkommend.

Maasse: Länge D. 57, Mx. 60, Min. 53. Breite D. 38 , Mx. 40, Min. 34.

194. Podiceps subcristatus, Rothhalsiger Steissfuss.

Ist nicht häufig, nur ein Gelege gesammelt von 2 frischen Eiern am 28. Mai.

Ankunft.

1867: 26. März.

1868: 1. April.

1869: 18. März.

Maasse: Länge D. 54 . Breite 33.

Abzug. 1867: nicht bemerkt. 1868: 12. October. 1869: 20 . "

195. Podiceps minor, Kleiner Steissfuss.

Ist ebenfalls selten, nur einige Mal auf dem Sokolowschen See beobachtet: am 4. Juli 1867, 28. Mai 1868, 2. October 1868.

196. Colymbus septentrionalis, Rothkehliger Taucher.

Am 19. November 1869 ein einzelnes Exemplar auf einem ziemlich grossen Mühlenteiche geschossen. Es war ein Junges von diesem Jahre.

\title{
Ueber das Nisten der Seidenschwänze in Deutschland
} sagt Dr. Gloger, dass in Oberschlesien Seidenschwänze mitunter genistet hätten und dass Jäger behaupteten, Pärchen mitten im Som- 
mer gesehen zu haben. Auch auf dem Hainichwalde, 1/2 Stunde von der Stadt Mühlhausen in Thüringen, sah der in unmittelbarer Nähe des Waldes wohnende Förster Bähr vor einigen Jahren im Sommer lange Zeit hindurch ein Paar Seidenschwänze, welche täglich unweit seiner Wohnung emsig nach Futter suchten. Leider hat aber derselbe kein Nest entdeckt. $\mathrm{Ob}$ er so eifrig und unablässig danach gesucht hat, wie es die Sache verdient, möchte ich bezweifeln. Jedoch an der Wahrheit seiner Aussage, das Vorkommen der Vögel betreffend, ist durchaus kein Zweifel. Gotha.

J. Hocker.

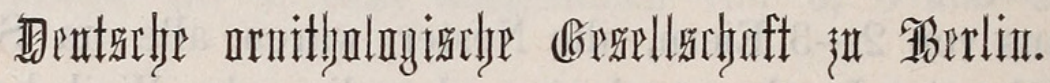

\section{Protokoll der XXXI. Monats-Sitzung.}

Verhandelt Berlin, Montag den 6. Februar 1871, Abends $7{ }^{1 / 4}$ Uhr, im Restaurant "Schlossbrauerei“ Unter den Linden 8.

Anwesend die Herren: Cabanis, Bau, Bolle, Freese, D'Alton, Golz, Sy und Brehm.

Von auswärtigen Mitgliedern: Herr Kammerherr O. v. Krieg er, aus Sondershausen.

Als Gast: Herr Dr. Hellma n n aus Gotha.

Vorsitzender: Herr Golz. Protokollf. Hr. Bau.

Der Secretär macht Mittheilung über die von auswärtigen Mitgliedern eingegangenen Zuschriften: Herr v. H e u g li n und Herr Nehrkorn senden der Versammlung besten Gruss und werden deren für das Journal bestimmte Mittheilungen besonders abgedruckt werden.

Herr G. v. K o ch hat sich der dankenswerthen Mühe unterzogen, eine Sammlung von Stellungen der Vögel zu veranstalten. Mit kunstgeübter Hand sind in geiungenen Umrissen sowohl ausser einheimischen Vögeln auch exotische Typen auf Octavtafeln radirt. Diese Sammlung soll in einigen Heften je zu 10 Tafeln veröfientiicht werden. Das Werkchen ist besonders für Ausstopfer bestimmt, da diesen selten gute Werke, deren es in Bezug auf lebendige, naturgetreue Stellungen der Abbildungen überhaupt nicht $\mathrm{zu}$ viele giebt, zugänglich sind. Z Zweck der Herausgabe ist der Wunsch, 


\section{$2 \mathrm{BHL}$ Biodiversity Heritage Library}

1871. "Ueber das Nisten der Seidenschwänze in Deutschland." Journal fu

r Ornithologie 19, 151-152. https://doi.org/10.1007/bf02259434.

View This Item Online: https://www.biodiversitylibrary.org/item/111231

DOI: https://doi.org/10.1007/bf02259434

Permalink: https://www.biodiversitylibrary.org/partpdf/141792

\section{Holding Institution}

Smithsonian Libraries

\section{Sponsored by}

Biodiversity Heritage Library

\section{Copyright \& Reuse}

Copyright Status: Public domain. The BHL considers that this work is no longer under copyright protection.

This document was created from content at the Biodiversity Heritage Library, the world's largest open access digital library for biodiversity literature and archives. Visit BHL at https://www.biodiversitylibrary.org. 